\title{
Water-Saving Irrigation System Using Risc Processor and Wsn
}

\author{
Chaitali R. Fule1, Prof. Pranjali M. Awachat, Prof.Dinesh Rotake \\ ${ }^{I}$ Department of Electronics\& telecommunication Engineering G. H. Raisoni Institute of Engineering and \\ Technology for women Nagpur, India \\ ${ }^{2}$ Department of Electronics\& telecommunication Engineering G. H. Raisoni Institute of Engineering and \\ Technology for women Nagpur, India \\ ${ }^{3}$ Department of Electronics\& telecommunication Engineering G. H. Raisoni Institute of Engineering and \\ Technology for women Nagpur, India
}

\begin{abstract}
As water supplies become insufficient and contaminated, there is an insistent require to irrigate extra efficiently in order to optimize water use. The sensor node gathers the information such as soil moisture to make the motor ON or OFF. The microcontroller receives the real-time data compares according to the defined value and processes those data which are transmitted from the sensor node. The system replaces the wired transmission with the wireless transmission, which reduces the costs in part and protection and improves the system's consistency and conservatory. It has improved purpose viewpoint.
\end{abstract}

Keywords: wireless sensor node,soil moisture sensor,water resources, AVR Atmega 16L

\section{Introduction}

In India irrigation in farms is mainly dependent on the monsoon,which is not considered as a reliable source of water due to which manual irrigation is applied to the farms. But its main drawback is underirrigation or overirrigation which results in soil salinity or water pollution respectively. Hence there is need of automated irrigation system. Main Drawback of existing system is that it is time based system i.e. the water applied is for particular time period irrespective of whether plant require water or not.Depending on the soil type, age of crop, type of crop, water content in soil, soil temperature, atmospheric temperature, type of irrigation plants are to be provided with water, which is called as intelligent irrigation system. In this project prototype of an Intelligent Irrigation system that allows intelligent control of the water applied to the three different nodes, according to the priority of crop, is designed and fabricated. The system has the capabilities to measure the water content in the soil, so it simultaneously collects these data from three nodes,compares the value and decides the condition of solinoid valve that is ON or OFF. The soil moisture sensor based on the soil moisture content will provide the amount of the water required for plant. Thus system can be used to study the water requirements for crops so irrigation can be scheduled efficiently.

There are different types of irrigation system

- $\quad$ Surface irrigation

- $\quad$ Localized irrigation

- $\quad$ Drip Irrigation

- $\quad$ Sprinkler irrigation

Surface irrigation is defined as the collection of purpose techniques where water is functional and dispersed over the soil surface by gravity. It is by distant the most general form of irrigation all the way through the world and has been skillful in many areas virtually unchanged for thousands of years.Surface irrigation is time and again referred to as flood irrigation, imply that the water allocation is uncontrolled and therefore, naturally inefficient. In reality some of the irrigation practice grouped under this name involves a significant degree of management (for example surge irrigation).

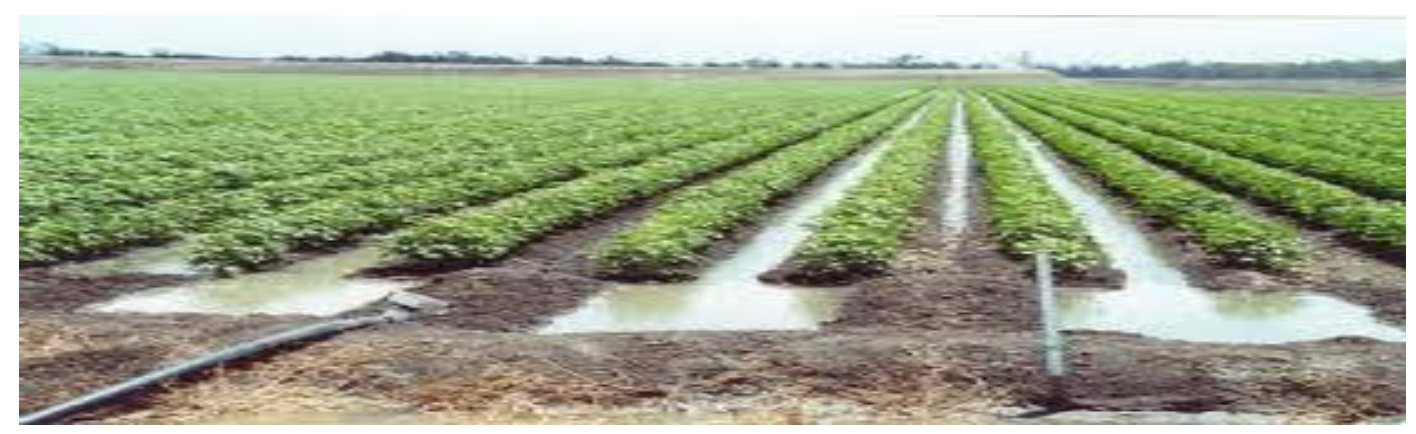




\section{Fig: Surface Irrigation}

Localized irrigation systems apply water directly where the plant is rising thus minimize water thrashing through fading from the soil. Such localized irrigation systems contain porous clay pots, porous pipes, and perforated plastic sleeves.

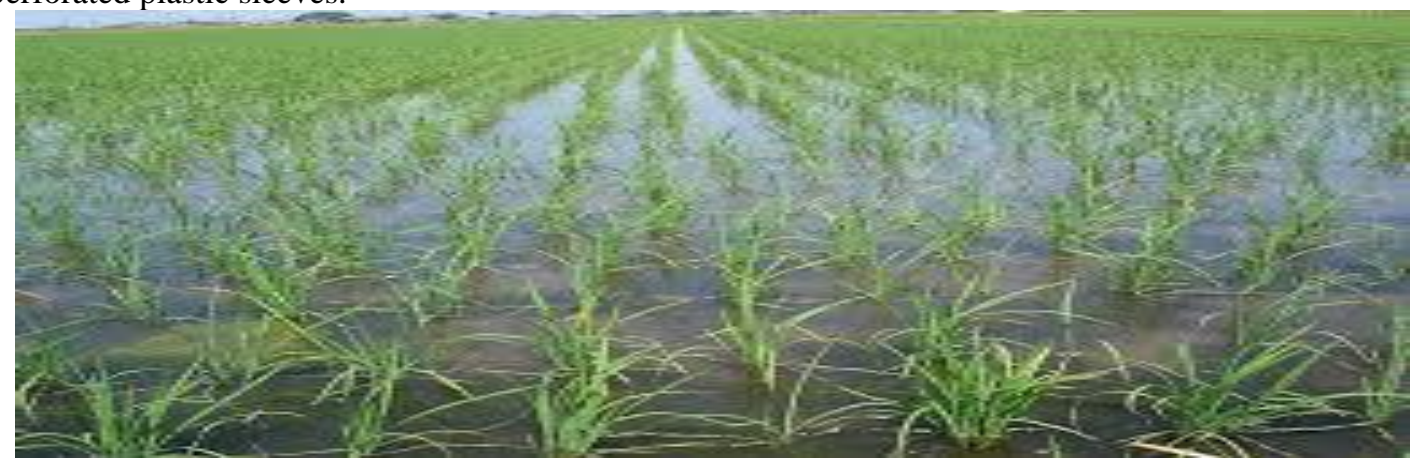

Fig: Localized Irrigation

drip irrigation, also known as trickle irrigation or micro irrigation , is an irrigation method that hoard water and sustenance by allow water to drip slowly to the roots of plants, either onto the soil surface or straight onto the root zone, through a network of valves, pipes, tubing, and emitters. It is done from beginning to end narrow tubes that deliver water directly to the base of the plant.

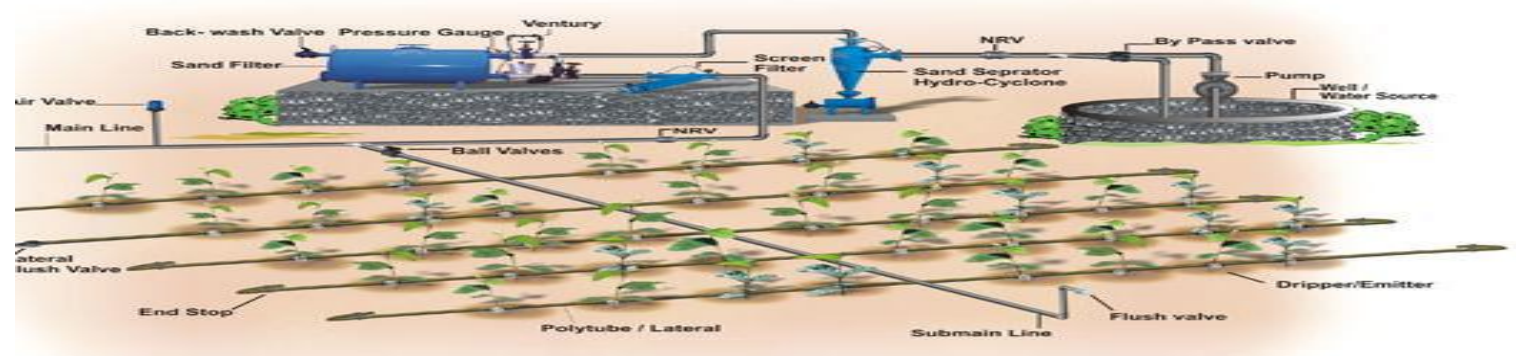

Fig: Drip Irrigation

Sprinkler Irrigation is a method of applying irrigation water which is parallel to rainwater. Water is spread through a structure of pipes typically by pumping. It is then sprayed into the air and irrigated complete soil surface through spray heads so that it breaks up into small water drops which fall to the ground. Sprinklers provide efficient coverage for small to large areas and are appropriate for use on all types of properties. It is also adjustable to nearly all irrigable soils since sprinklers are available in a wide range of discharge capacity.

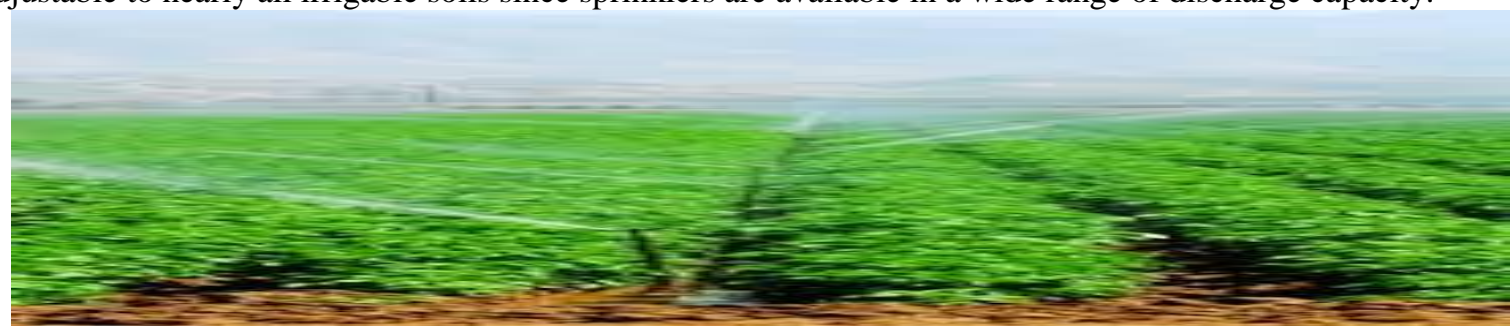

Fig: Sprinkler Irrigation

\section{Methodology}

The Irrigation using soil moisture sensors and Microcontroller is an special apparatus that can automatically feed plants with water according to their need without farmer's interference. Design of an irrigation system will manage stream of water into the field automatically. The system comprises of Soil moisture sensors to know the status of the water level in the farm; Solenoid valves for controlling water flow to the farm;; and a controller for the data processing and to control all the operations. 


\section{System Architecture}

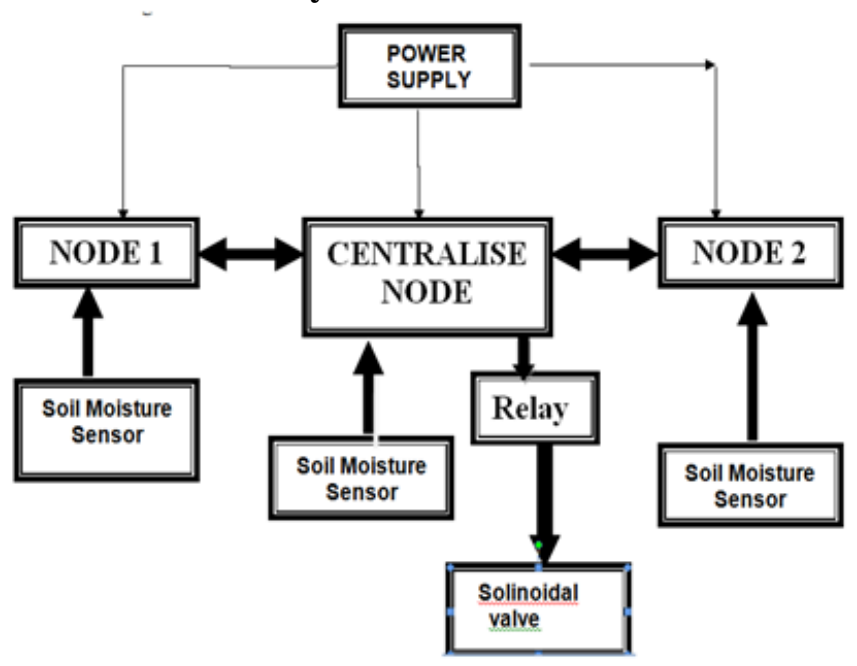

Figure 1: Block Diagram

System architecture is shown in the block diagram (Figure 1).

A soil moisture sensor are excited by giving suitable power supply of $5 \mathrm{~V}$ each and is connected to lower four bits of Port A. Port A pins are internally connected to ADC on chip which is of 10 bit resolution. The sensor senses the amount of moisture present in the soil and presents an output in the form of analog voltage ranging between $1.7 \mathrm{~V}$ (fully saturated condition) to $4.5 \mathrm{~V}$ (completely dried condition) respectively. The sensor values which are in analog form are converted to digital values and are stored in the ADC data registers ADCL and ADCH respectively. The average of all the sensor values are computed and is used to decide the condition of the relay which controls the valve and thus watering the field for predefined amount of time.

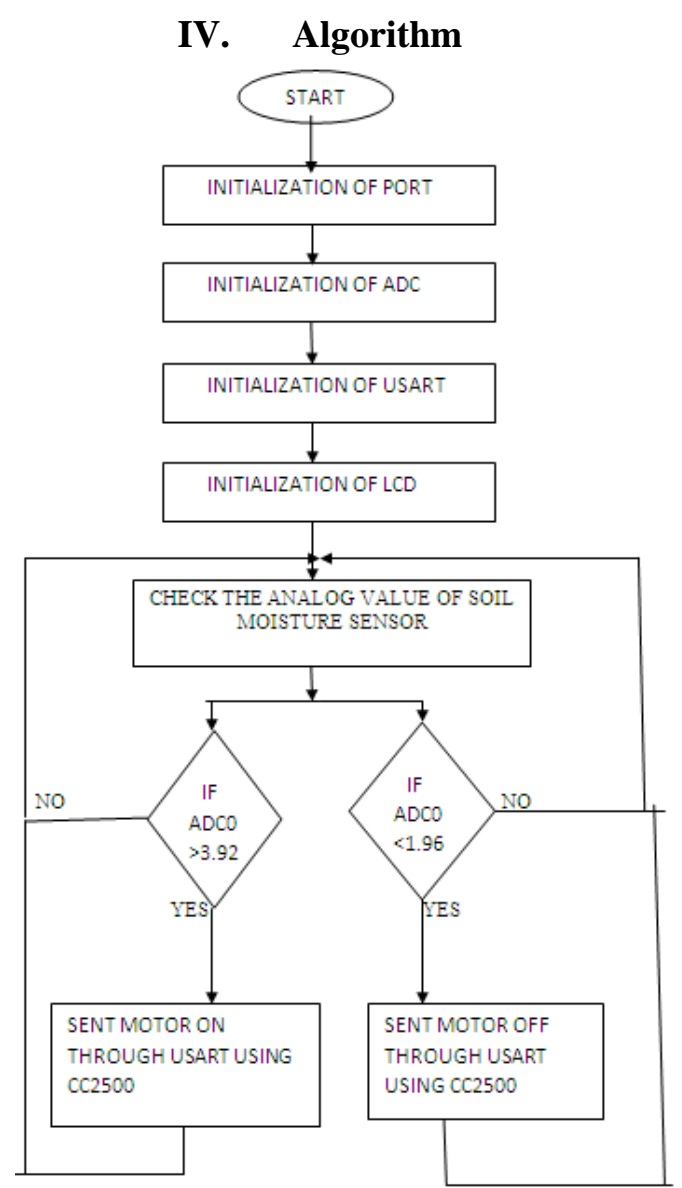




\section{TEST}

After the designing of the system for indication of soil moisture, we implemented it in several test runs. As the water motor is mostly an analog unit and our designed circuit is a digital unit a complete isolation has to be provided. Isolation is to be provided because if the digital device produces a back current it can damage the entire system. And also we don't know whether the user will use all analog or all digital or some analog and some digital. So relay is one of the solutions for this problem.

When soil moisture value is $1.96 \mathrm{~V}$, the relay will be in normally open condition. Output of the sensor is connected to the microcontroller and it decides according to algorithm that soil is wet and motor will remain in off state. LCD displays the digital value of moisture, that is, 19 and complete wet and also motor is off.

When soil moisture value is $3.92 \mathrm{~V}$, the relay will be in normally close condition Output of the sensor is connected to the microcontroller and it decides according to algorithm that soil is dry and motor turns on. LCD displays the digital value of moisture, that is, 39 and complete dry and also motor is on.

INPUT: Analog value of Soil Moisture Sensor

OUTPUT: output was obtained in various stages,

$>\quad$ After the user defined time microcontroller got logic 1

$>\quad$ LCD displays value of moisture content of soil.

$>\quad$ LCD displays complete dry if value of moisture content is greater than 15 and complete wet if the value of moisture content is less than 15 .

$>\quad$ LCD displays state of motor (motor on/off).

\section{RESULT}

Experimentation and validation of the system is performed considering various cases as stated earlier and accordingly following results are obtained

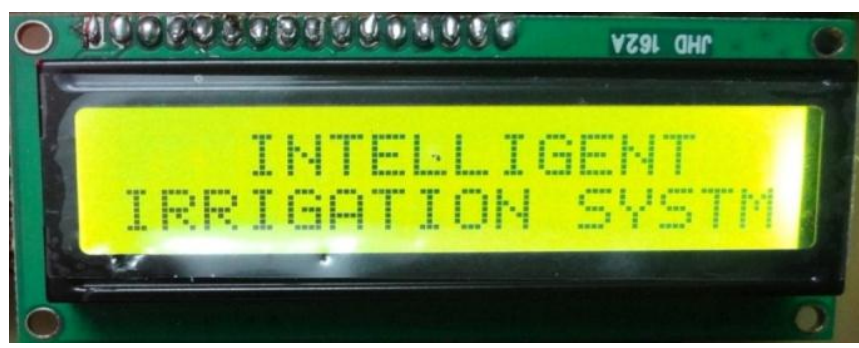

fig. 2: Initialization of the system

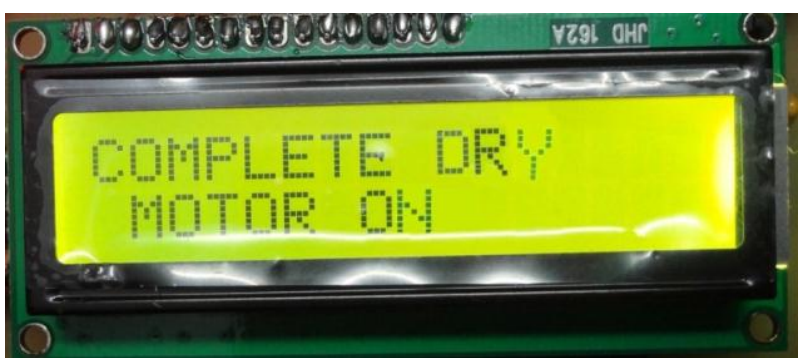

fig. 3: Displays when value is less

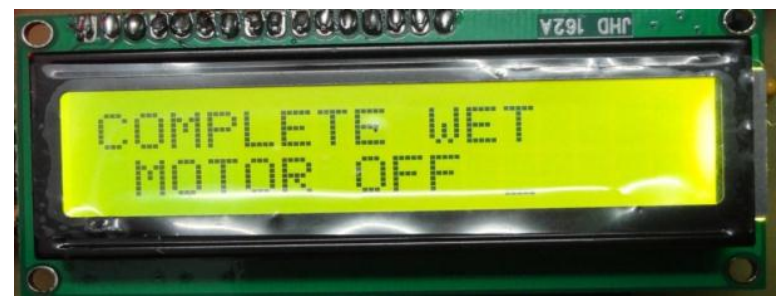

fig. 4: Displays when value is maximum 
Result obtained are compared with various factors and accordingly graphs are plot as follow:

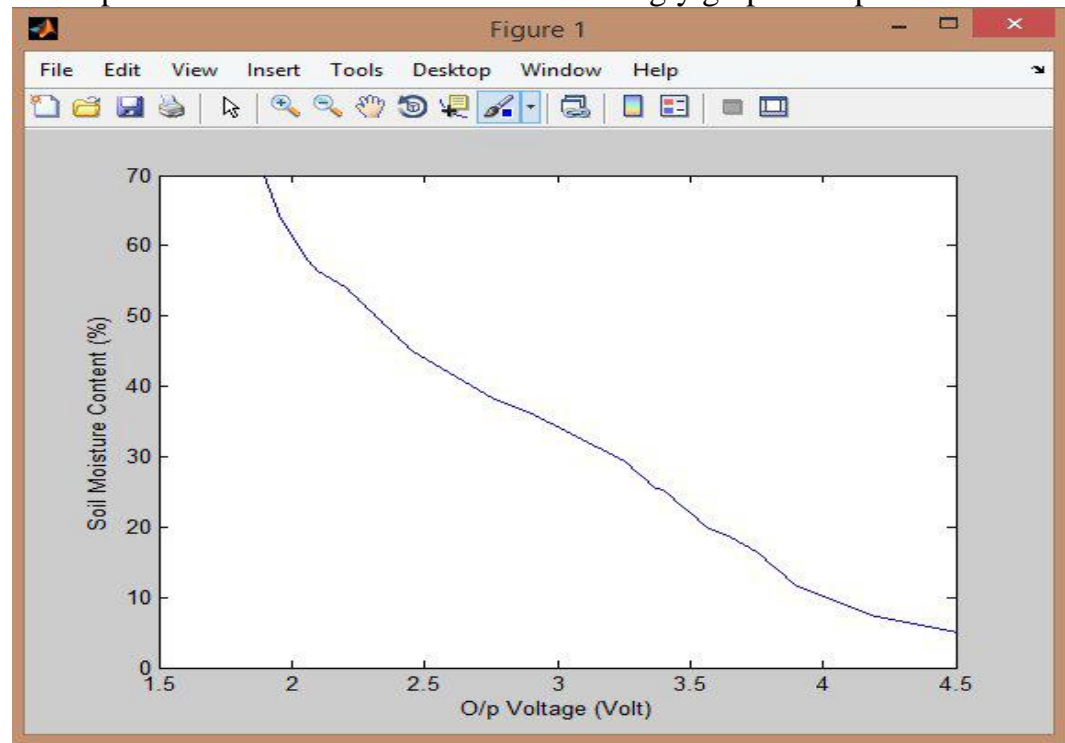

fig. 5 :O/P voltage Vs Soil Moisture Content Graph

According to reading, O/P voltage Vs Soil Moisture Contentn Graph is plotted which shows that as output volt increases soil moisture content decreases.

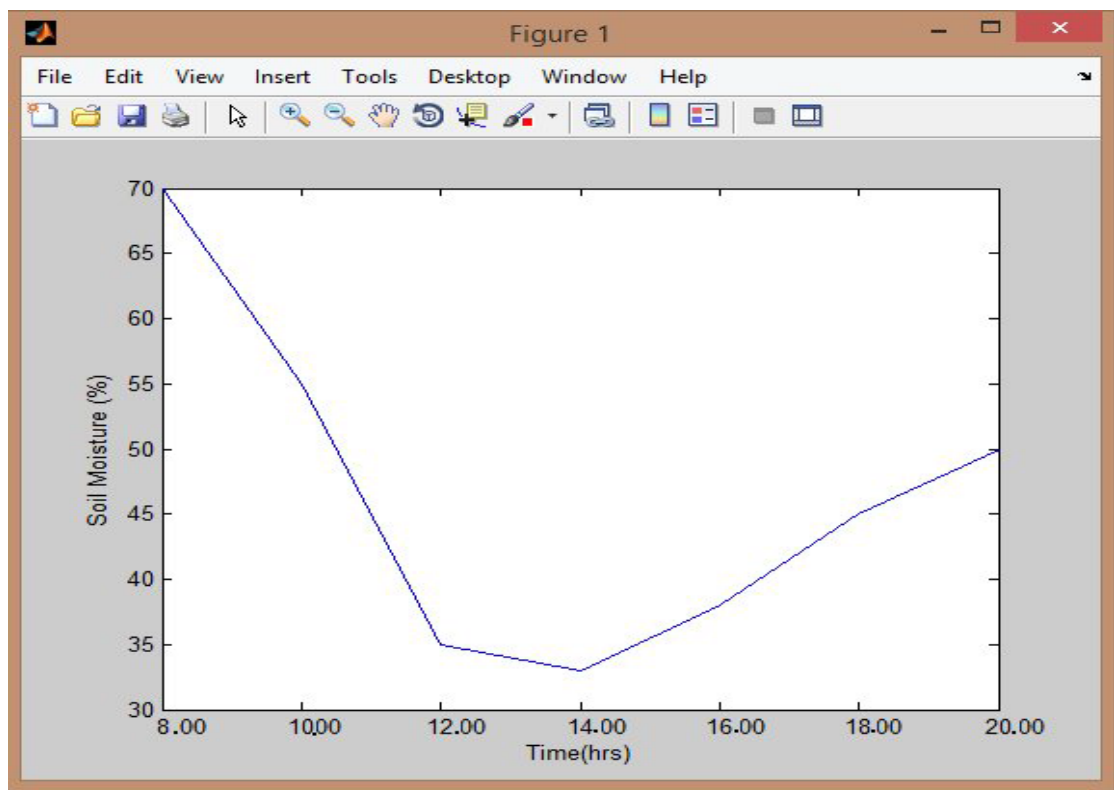

fig. 6: Time Vs Soil Moisture Content Graph

As per the reading Time Vs Soil Moisture Content Graph is plotted which represents soil moisture decreases till 2pm and afterwards gradually increases.

\section{Conclusion}

The circuit for the system indicating soil moisture level in field/lawns using irrigation system net has been designed and created on the PCB board and the various connections have been made. The designing of PCB board has been done using EAGLE software and the encoding of AVR has been done using embedded C language by WINAVR. Thus we have performed the indication operations of moisture using various types of soil and performed it on same kit successfully. 


\section{Future Scope}

1)More parameters can be considered so that intensive and useful data can be applied for irrigation.

2) System can be designed according to the water available in the sump and electricity available for irrigation.

3) System can be designed considering various irrigation system like surface irrigation, flood irrigation system.

4) New technologies such as Remote Sensing (RS), Global Positioning System (GPS), Geographical Information System (GIS) and Wireless Sensor Network (WSN) can also be used to find geometrical environment and accordingly irrigation can be implemented.

\section{References}

[1]. Joaquin Gutierrez, Juan Francisco Villa-Medina, Alejandra Nieto-Garraway, and Miguel Ángel Porta- Gándara “Automated Irrigation System Using a Wireless Sensor Network and GPRS Module " IEEE 2013

[2]. Jia Uddin, S.M. Taslim Reza, Qader Newaz, Jamal Uddin, Touhidul Islam, and Jong-Myon Kim,“Automated Irrigation System Using Solar Power" (C2012 IEEE

[3]. Thomas J. Jackson, Fellow, IEEE, Michael H. Cosh, Rajat Bindlish, Senior Member, IEEE, Patric J. Starks, David D. Bosch, Mark Seyfried, David C. Goodrich, Mary Susan Moran, Senior Member, IEEE, and Jinyang Du "Validation of Advanced Microwave Scanning Radiometer Soil Moisture Products", IEEE 2010

[4]. Andrew J. Skinner and Martin F. Lambert, "An Automatic Soil Pore-Water Salinity Sensor Based on a Wetting-Front Detector" 2010 IEEE

[5]. Samy Sadeky, Ayoub Al-Hamadiy, Bernd Michaelisy, Usama Sayedz, “ An Acoustic Method for Soil Moisture Measurement ”, IEEE 2004. 